
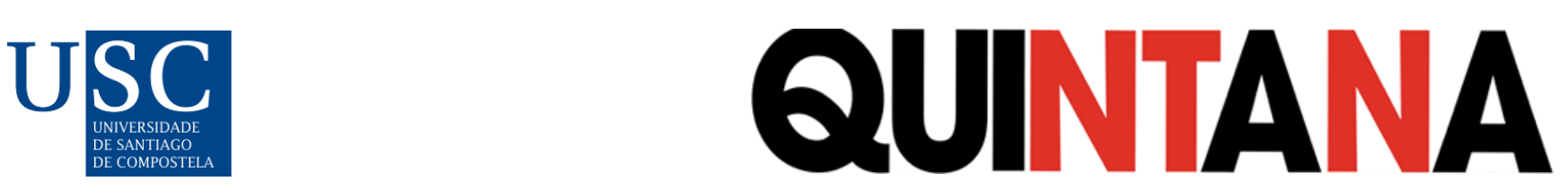

Quintana: revista do Departamento de Historia da Arte, (20), 2021. ISSN-e: 2340-0005

https://doi.org/10.15304/quintana.20.7199

Colaboracións

\title{
EL AURA DE LA COPIA. NOTAS A PARTIR DE COPIA CERTIFICADA (A. KIAROSTAMI, 2010)
}

\author{
María del Carmen Molina Barea ${ }^{1, a} \mathbb{D}$ \\ ${ }^{1}$ Universidad de Córdoba, España \\ a152mobam@uco.es
}

Recibido: 22/10/2020; Aceptado: 08/01/2021

\section{Resumen}

El presente trabajo pretende desarrollar un análisis filosófico del debate entre "original y copia" en el ámbito de la obra de arte, a partir de la película Copia certificada (2010) del director iraní Abbas Kiarostami. Con este objetivo, el artículo aborda los problemas esencialistas derivados de la obra de arte original y la supuesta ilegitimidad de la copia, interrogando sus implicaciones ontológicas al respecto de las nociones de autenticidad, reproducción y falsificación. En este proceso se someterán a revisión las teorías de Arthur C. Danto sobre la Brillo Box de Andy Warhol, la pérdida del aura pronosticada por Walter Benjamin, y las "auras frías" de la obra fetichista según José Luis Brea, para terminar planteando el juego de vaivenes subjetivantes entre original y copia, de modo que a esta se le reconozca también carácter original por sí misma.

Palabras clave: original; copia; aura; autenticidad; reproductibilidad

\begin{abstract}
The present paper aims to develop a philosophical analysis of the "original vs. copy" debate in the artistic field, taking as a starting point Certificated Copy (2010), by the Iranian filmmaker Abbas Kiarostami. To this end, the paper addresses essentialist issues regarding the work of art as an original, and the alleged illegitimacy of the copy, thus questioning their ontological implications in what respects the notions of authenticity, reproduction and falsification. In this process several theories will be revisited, for instance Arthur C. Danto's view on Andy Warhol's Brillo Box, along with Walter Benjamin's prediction of the diminishing aura, and fetishistic "cold auras" according to José Luis Brea. All of this in order to illustrate the subjectivating fluctuation among originals and copies and ultimately state that the copy is original by itself.
\end{abstract}

Keywords: original; copy; aura; authenticity; reproductibility

\section{INTRODUCCIÓN: SOBRE LA EXPERIENCIA ONTOLÓGICA DE LA COPIA}

¿Tan semejante es la copia al original que hay duda en saber si es ella propia?

Copyright $\odot$ Universidade de Santiago de Compostela. This is an open access article distributed under the terms of the Creative Commons Attribution-NonComercial-NoDerivatives 4.0 International (CC BY-NC-ND 4.0) License. 
La cinta de Abbas Kiarostami Copia certificada (2010) ocupa en la filmografía del cineasta iraní un lugar destacado por su reflexión sobre el estatuto ontológico de la obra de arte como objeto único, esencialmente distinto de las reproducciones, que se estiman el negativo falso de un original verdadero. En este sentido, la película aborda el debate en torno al original y su doble no auténtico, la copia, una problemática que, en forma de alter ego cinematográfico, Kiarostami llevó a su máxima expresión en Close up (1990). En concreto, Copia certificada toma como motivo argumental la publicación de un libro -titulado igual que la película- cuyo autor, James Miller (interpretado por William Shimell) dedica a estudiar la relación entre el original y la copia de obras de arte. El diseño de la portada del libro evidencia su contenido: una imagen enfrentada de David contra David. Un "cara a cara" entre el original de Miguel Ángel y su copia. Según se explica en la película, el libro se basa en una anécdota sobre la célebre escultura y la copia ubicada en la Piazza della Signoria de Florencia.

Cuenta el escritor que estando un día en dicha plaza, observó a una madre con su hijo frente a la copia del David. El niño miraba la estatua con la admiración que solo se le concedería al original, pero el pequeño ignoraba que la obra auténtica se encuentra en la Galleria dell' Accademia, pues su madre no le había revelado ese dato. Para el niño, la copia era tan original como el original mismo. Partiendo de esta idea, en las páginas que siguen intentaré constatar que el antagonismo de “original y copia” es, en realidad, el de "original y original negado", replanteando el aura benjaminiana y la lábil frontera entre copia y falsificación. Si a la copia -entendida como imitación (mímesis)- se le reconocen propósitos “honrados", por ejemplo pedagógicos o de conservación, se la denomina réplica, o si tiene fines de consumo legal, se llama reproducción, pero si se conduce con intenciones "maliciosas" o "innobles", se trata de una falsificación porque no se limita a ser un doble reconocido, esto es, un plagio declarado (réplica o reproducción), sino que juega a ser el original mismo. Pretende hacerse pasar por él y ocupar su lugar para engañar suplantando la identidad verdadera, motivo por el cual se la toma por fraude, o sea, la mentira de un original. Estaríamos, por lo tanto, ante una obra falsa. La falsificación es un plagio no declarado que, aún más, aspira a operar como el original.

En este ámbito, según la distinción de Cesare Brandi $(2003,66)$, se dan tres casos fundamentales: 1. Reproducción que imita el estilo artístico de un autor o de un periodo histórico con fines de placer estético o documentación; 2. Imitación con intención de llevar a engaño acerca de la época, material o autor; 3. Introducción de la copia en el mercado, a pesar de no haber tenido intención de engaño. El primer caso se corresponde con la copia o imitación, mientras que el segundo y tercero abarcan la falsificación. En consecuencia, Brandi señala que la clave para diferenciarlos está en el dolo, en la intención que preside la realización de la copia, pues "solo el animus determina el juicio de falso" y no tanto los materiales o procedimientos empleados. Estos pueden, en efecto, plagiar los originales, fingirse aquellos que se aplicaron en el original, pero en último extremo, como observa Brandi, en sí mismos son "auténticos". El síntoma de falsedad procede, más bien, de la intencionalidad desleal respecto del objeto considerado original y legítimo. "Así pues, en la base de la diferencia entre copia, imitación, falsificación, no hay una diversidad específica en los modos de producción, sino una intencionalidad distinta". (Brandi 2003, 66) Además de por su intención, la falsificación adquiere carácter falso en contraste con el original. De ahí que el estatuto ontológico de una obra falsa sea condicional; el efecto derivativo de una comparación: 
Se malinterpreta la falsificación si se considera que puede estudiarse desde un punto de vista pragmático, como historia de los métodos de fabricación de las obras falsas, en vez de partir del concepto de obra falsificada. Este planteamiento se explicará de inmediato si se piensa en que una falsificación no lo es hasta que no se reconoce como tal, porque la falsedad no se puede considerar realmente como una propiedad inherente al objeto, en cuanto que, incluso en el caso límite en que la falsedad radique principalmente en sus consistencia material diferente, como es el caso de las monedas, tal falsedad resulta por comparación con la aleación que compone las monedas antiguas, pero la aleación en sí no es falsa, es genuina. [...] Era premisa indispensable evidenciar cómo la falsedad radica en el juicio y no en el objeto, ya que de otro modo no se justificaría cómo un mismo objeto, sin variaciones de ninguna especie, puede ser considerado imitación o falsificación en función de la intencionalidad con que fue producido o puesto en circulación. (Brandi 2003, 65)

Es acuerdo generalizado que la experiencia que obtenemos ante una copia, ya sea réplica, reproducción o falsificación, no es comparable a la que tendríamos frente al original. Como decía el personaje de Masatoshi Nagase en la película Paterson (Jim Jarmusch, 2016), leer poesía traducida es como darse una ducha con impermeable. Una traducción nunca es el original, pues difícilmente logrará equiparar el grado de sutileza, giros armónicos e imágenes lingüísticas de este, por lo que cae en un caso de traduttore traditore. La copia, vista bajo el símil de la traducción, no sería en realidad un ente derivado, sino un original en sí misma, que alude a otro original al cual no hace justicia, y así incurre en infidelidad, en traición a la verdad del original. Caso extremo de este fenómeno es el de Han van Meegeren, controvertido copista de Vermeer, cuyas falsificaciones devienen piezas originales por derecho propio, o el de Elmyr de Hory, tratado por Orson Welles en F for fake (1973). Pero si la copia, como también la traducción, se entiende por el contrario como una versión, interpretación, o ejecución del original, ¿no sería esta una forma de actualizarlo, de poner plenamente en acto dicho original? Es más, ¿no sería acaso una manera distinta de potenciar el carácter original de la copia misma? En la experiencia del niño de Copia certificada, la copia del David funciona con más intensidad que el auténtico original. Para el niño no importa realmente que este se encuentre en la Accademia; el de la Piazza della Signoria, ese es su original.

Esto encuentra cierto matiz de contraste en la distinción que establece Nelson Goodman (2010, 110) entre arte autográfico y arte alográfico. La pintura y la escultura son autográficas, esto es, artes en las que se plantea una relación de exclusión entre el original y la copia, mientras que la música y la literatura son alográficas, lo que quiere decir que la relación entre original y copia produce instancias o ejemplares. La ejecución de una sinfonía de Mozart por parte de una orquesta no es la copia del original mozartiano sino una instancia del mismo, no en vano, una interpretación. De igual forma, el libro Moby Dick que adquiero en la tienda no es copia del original de Melville, sino un ejemplar, y por lo general, en una versión traducida. Según Goodman, las artes plásticas usan símbolos densos, cuya copia altera el aspecto representativo y la relación autográfica con el original. En el extremo opuesto, las artes alográficas usan símbolos articulados, que sí se pueden copiar sin problema de dependencia representativa.

De este modo, la copia autógrafa no hace justicia al original, al contrario que la actualización interpretativa alográfica. Además, la primera corre el riesgo de caer en la falsificación si incurre en un hecho doloso. Sobre si esta puede ser reconocida como original se pronuncia afirmativamente Cesare Brandi en lo que atañe a la maestría técnica, pero dubitativamente cuando la copia se presenta como una interpretación autónoma del estilo del original. En esta situación, si busca el engaño no se puede tomar por original. A este respecto Brandi comenta el caso de Van Meegeren, al que finalmente considera un autor de falsificaciones, no originales, porque mintió sobre la fecha de datación intentando pasarla por auténtica. Aquí concurre la denuncia antes referida del traduttore 
traditore. Pero si la copia es, en cambio, una interpretación en sentido alográfico, entonces sí estaríamos ante un original propio, que además procede de manera legítima para con el original.

En cualquier caso, de acuerdo con Goodman, la copia del David no sería una instancia o ejecución interpretable del original de Miguel Ángel, puesto que una copia escultórica, por perfecta que sea, manifiesta su imposibilidad de lograr una total equivalencia con las propiedades autográficas presentes en el original. Pero precisamente porque no puede ser copiada hasta sus mínimos detalles, una escultura es ante todo interpretada, ejecutada, performada. "A sculpture cannot merely be copied but always only staged or performed". Esta frase, inspirada en la obra filosófica de Boris Groys, se incluye en el proyecto del artista alemán Oliver Laric titulado, no casualmente, Versions (2009), en el que se cuestionan aspectos relacionados con la copia, el original y su reproducción. El proyecto fue premiado para colaborar con el museo británico The Collection \& Usher Gallery de Lincoln en el escaneo 3-D de su colección de esculturas. Se buscaba crear un archivo digital que pudiera ser visitado por usuarios de todo el mundo y descargarse gratuitamente las imágenes autentificadas de las obras. El referido proyecto tenía carácter artístico de por sí y como tal pasó también a los fondos del museo. Lo relevante del trabajo de Laric se halla en el replanteamiento de los límites entre el original y su reproducción, y en la duda abierta de si la reproducción -incluso digital- permanece fiel a la autenticidad de aquel.

Dicho lo anterior, puede que la diferencia entre original y copia no radique, como señala el teórico y crítico de arte Arthur C. Danto, en el factor epistemológico sino en el ontológico; no se trata de una diferencia que se resuelva en el plano perceptivo, sino en respuesta a la cuestión del ser. Así, en el intento de identificar por un lado la Brillo Box del supermercado y por otro la Brillo Box de Andy Warhol, Danto sostiene que la clave para distinguir el producto original de la obra de arte que lo copia no se localiza en las propiedades representativas, sino en su lectura teórica, de forma que el rastreo de lo verdadero requiere una tarea interpretativa:

El problema, tal como lo vi y todavía lo veo, surgió inicialmente con Warhol y su Brillo Box, que era perceptivamente idéntica a las cajas cotidianas en las cuales el producto Brillo era enviado desde la fábrica hasta el almacén y de ahí al supermercado; tan parecida que la cuestión de cómo diferenciar una de otra se complicaba: y esto lo entendí como la cuestión de distinguir el arte de la realidad. Y no me refiero a distinguirlos epistemológica sino ontológicamente, pues más tarde o más temprano alguien descubriría que una estaba hecha de madera contrachapada, y la otra no. La cuestión era si la diferencia entre el arte y la realidad podría consistir en unas diferencias detectables como esa misma. Yo no lo creía, pero desde el principio mi estrategia fue averiguar cómo puede haber diferencias que no sean diferencias de percepción. En mi opinión tenía que haber una teoría del arte que pudiera explicar la diferencia (Danto 2013, 143).

\section{LOS CIPRESES O EL SIGNIFICADO DEL ARTE}

We are giving you the reproduction so you will
want no longer feel any need for the original.
-Travels in Hyperreality, Umberto Eco-

Hay una secuencia en la película de Kiarostami en la que sus dos protagonistas, el mencionado escritor James Miller y la vendedora de antigüedades que encarna Juliette Binoche, viajan en coche hacia un pueblo de la Toscana. En el trayecto conversan sobre el significado de la obra artística. A James le interesa la mirada que el espectador proyecta sobre la obra; una mirada subjetiva, creadora, inventiva. Pues la obra, afirma, solo tiene el valor que le otorga la persona que la mira. 
Aquella sinfonía de Mozart o la novela de Melville, ¿seguirían siendo arte si nadie la interpretase y leyese, si nadie actualizase su potencial ser-arte? En definitiva, ¿el objeto es arte por sí mismo, o es arte porque alguien lo contempla? El eco de Berkeley y la denuncia heideggeriana del olvido ontológico laten en el fondo de esta pregunta, retomando el dilema entre ser y aparecer, al que solo Nietzsche $(1998,52)$ parece dar respuesta concluyente: "Hemos eliminado el mundo verdadero: ¿qué mundo ha quedado?, ¿acaso el aparente?... ¡No!, ¡al eliminar el mundo verdadero hemos eliminado también el aparente!”.

En esta tesitura se posiciona la pareja de Copia certificada en el esfuerzo de dilucidar una aproximación al problema. James sostiene que la obra adquiere la esencia que el sujeto le atribuye, de lo cual infiere que no importa si aquella es una copia, una obra de mala calidad, o incluso un objeto común. El valor del objeto no es una propiedad intrínseca. A este respecto, a lo largo de la conversación surge el ejemplo de la Coca-cola de Andy Warhol, que James explica de la siguiente forma: "Se coge un objeto corriente, lo metes en un museo y cambias la forma de mirarlo de la gente. Lo que importa no es el objeto sino tu percepción del mismo". Según esta afirmación, que participa de la enseñanza duchampiana de los ready-mades, del espectador depende que cualquier objeto, al margen de su calidad o autenticidad, se convierta en algo artístico. Está en manos del sujeto que el objeto, conforme al famoso dicho de Píndaro, se haga lo que es: en este caso, una obra de arte. El espectador hace posible que la obra llegue a ser; es el sujeto quien cumple la promesa aristotélica del ser en potencia. Lo cual, por otra parte, no justifica que todo lo que puede ser arte efectivamente lo sea.

La pregunta, en todo caso, no es ya “¿Qué es arte?”, dado que cualquier cosa puede serlo, sino “¿Cuándo es arte?”. Con esta fórmula ilustraba Goodman $(1990,98)$ que una piedra al borde del camino no es arte, pero cuando la misma piedra forma parte de una instalación artística en la sala de un museo varía su ontología, pues varía también la forma de mirarla y valorarla. El ser es circunstancial, la esencia resulta contingente. Por tanto, ¿cuándo una botella de Coca-cola es arte? Es decir, ¿en qué situación un objeto utilitario convencional, sacado de su contexto y colocado en un museo, se convierte en obra artística? Una primera respuesta podría ser: cuando lleva la firma de Andy Warhol. En estos términos se pronuncia el personaje de Binoche: "Si te llamas Jasper Johns puedes hacer eso". Andy Warhol, como Jasper Johns, transfigura (en la expresión de Danto) una Coca-cola en obra de arte por el toque de gracia de su mano privilegiada, la del artista genio, un ser iluminado, distinto del resto de mortales.

Esta rémora romántica del artista divino -deus artifex- nutre la ácida carcajada de creadores como Piero Manzoni, que mientras se benefician del sistema cultural satirizan sobre las bases de su funcionamiento. Las latas de Merda d'artista o los globos de "aliento de artista" son ejemplos rotundos. En ambos casos, sustancias comunes y abyectas se tornan obras de arte por el hecho de haber sido producidas por un artista. Esta ecuación, la de que el arte es lo que hacen los artistas, alumbra fenómenos tan histriónicos como el de las "esculturas vivientes": personas que adoptan una postura escultórica y permanecen quietas en esa pose una vez que Manzoni les estampa su firma sobre la piel. La rúbrica del artista, allí donde se inscribe, transforma la esencia del objeto, no importa cuál, en arte. Sin duda Marcel Duchamp abrió un camino sugerente cuando firmó como R. Mutt, mutando un urinario en La fuente.

De esto se desprende que el nombre del autor se asume como sello de calidad que acredita que el objeto es arte y lo autentifica como tal. Llevando la firma del artista, el objeto se venderá por altas sumas en las salas de subastas. De ahí que el nombre del autor sea una marca de autoridad y un criterio basilar para diferenciar el original de la copia. Pero Roland Barthes $(1994,71)$ ya advirtió 
que el nacimiento del lector se paga con la muerte del autor. ¿Hasta qué extremo el espectador no es también autor de la obra? Performances y happenings quiebran la separación entre la esfera del artista y la del público. Asimismo, el Arte Relacional desarrolla al máximo lo que Nicolas Bourriaud $(2008,17)$ define como "estado de encuentro" entre el artista y el espectador-manipulador, sin cuya participación la obra resulta inviable. Si consideramos además la corriente teórica Everyday Aesthetics, teorizada por Yuriko Saito, que hace de las acciones diarias una vivencia artísticamente experimentada a partir de la dimensión estética de los objetos cotidianos (non-art objects), llegamos a la conclusión, ya anunciada por Joseph Beuys de que, en realidad, todos somos artistas.

Así que no solo puede hacerlo alguien que se llame Jasper Johns. "Si tu nombre es Marie también puedes", responde James. Marie, la hermana de Binoche en la película, se nos describe como una mujer de preferencias sencillas y elecciones pragmáticas, que mira a su simple y común marido con tal admiración que "cambia su valor", al igual que el niño que veneraba la copia del David. Pero a personas anónimas como Marie no las secunda el "mundo del arte"; su criterio no recibe la aprobación de la institución o el refrendo de las salas, ni el respaldo del mercado o del coleccionismo, como sí sucede con los artistas de renombre. Por lo tanto, a la pregunta de “¿Cuándo una Coca-cola es arte?", otra posible respuesta sería: cuando está en un museo. La institución cultural ratifica el objeto como original, le da el visto bueno y lo incorpora a su colección. En consecuencia, los visitantes asumen sin mayor cuestionamiento que todo lo que está contenido entre los muros del museo es arte por la sola razón de estar ahí, mientas que lo que se encuentra fuera no lo es. En este sentido resulta reveladora la broma de unos estudiantes en el Museo de Arte de San Francisco en 2016. Sin que nadie lo apreciase, los adolescentes dejaron unas gafas en el suelo, haciendo creer al resto de visitantes que se trataba de una obra de arte más.

No importa de qué objeto se trate; si está en un museo el espectador se aproxima con la reverencia debida a un objeto de culto, único e irrepetible. Y así, lo que en otro contexto habría recibido una reacción cotidiana (alguien recoge las gafas y las deposita en objetos perdidos, por ejemplo), reviste en el museo un tratamiento ritual que rinde tributo a un original. Si, como decía el personaje de Shimell, cualquier objeto que se introduce en un museo cambia la percepción que se tiene de él, la clave para diferenciar arte de lo que no lo es se encontraría en la Teoría Institucional de George Dickie, según la cual -como en Danto, aunque por diferentes motivos- la simple percepción de un objeto no comunica su estatus de obra de arte (Mecacci 2016,62), sino que es el marco en el que se encuentra el que le confiere su condición artística. Para Dickie, solo lo producido dentro del marco institucional del mundo del arte puede ser obra artística: "Por aproximación institucional entiendo la idea que las obras de arte son arte como resultado de la posición que ocupan dentro de un marco o contexto institucional. La Teoría Institucional es, pues, una suerte de teoría contextual”. $(2005,17)$

No obstante, conviene replantear el alcance de la Teoría Institucional, ya que, por una parte, obvia el hecho de que hay objetos externos al museo que también pueden ser obras de arte. Esto es aplicable al análisis de Boris Groys $(2008,15)$ sobre el funcionamiento del espacio sagrado-museal como archivo en cuyo interior se atesoran los objetos más representativos del ámbito profano que se halla de puertas hacia fuera. Y por otra parte, la teoría de Dickie no tiene en cuenta que incluso dentro del marco museístico puede ocurrir que un objeto no se considere obra de arte. Esto es, aun dentro de un museo hay objetos que la institución propone como arte pero que para el espectador no funcionan como tal. Véase el caso de la instalación de Sara Goldschmied y Eleonora Chiari titulada ¿A dónde vamos a bailar esta noche?, expuesta en el Museo Bolzano de Milán en 2015. La obra, que estaba realizada con botellas, copas y restos de lo que podría haber sido una gran fiesta, fue 
desmantelada por la señora de la limpieza, que la interpretó como lo que parecía y no como una creación artística.

Así pues, al igual que preguntábamos sobre la Coca-cola, ¿en qué circunstancia unas botellas esparcidas por el suelo son arte? Hasta en el interior del museo se pueden tomar por basura. De modo que la clave no está tanto en el marco contextual como nuevamente en la interpretación que el individuo aplica al objeto y que le dota de un valor del que carecería en caso contrario. Continuando lo dicho por el escritor de Copia certificada, la respuesta al interrogante de Goodman sería entonces: algo es arte cuando cambia nuestra percepción del objeto o, desde la perspectiva hermenéutica de H. G. Gadamer, cuando entramos a jugar con el objeto en el círculo interpretativo que alcanza la fusión de horizontes. En efecto, solo si se "juega", un palo puede convertirse en caballito de madera, a ojos de Gombrich. El poder creador de esa mirada lúdica dirigida al objeto es capaz incluso de otorgar valor artístico a una banana pegada a la pared por indicación de Maurizio Cattelan. ¿En qué momento dejó de ser un producto comestible para convertirse en obra de arte? Si es que dejó de serlo alguna vez, habida cuenta de que fue engullido por un visitante. Pero aun siendo comido, sigue tratándose de arte, pues quien lo hizo era un artista en plena performance. El circuito de transfiguración del objeto cotidiano en obra de arte se presenta aquí como un bucle sin término.

Constatamos, pues, que aunque no todo es arte, todo puede llegar a serlo. Afirmar esto, sin embargo, no da validez al beneplácito del "todo vale", porque para que una cosa sea arte necesita un "cuándo", una circunstancia en la que la mirada del espectador le aporte ese valor ontológico. El catedrático de Estética José Jiménez $(2004,17)$ resume el problema al declarar que "arte es todo lo que llamamos arte". He aquí lo urgente: encontrar el criterio de cuándo llamar arte a un objeto. La disolución de fundamentos que asienta la posmodernidad tras la muerte del arte no lleva aparejada necesariamente la completa desaparición de patrones de referencia. Es necesario establecer el principio del "cuándo". En una época en la que, según Th. W. Adorno $(2004,9)$ "ha llegado a ser obvio que ya no es obvio nada que tenga que ver con el arte”, ¿cómo diferenciar el arte de un objeto común, el original de la copia? En busca de lo auténtico, no sirven ya el nombre del autor ni el marco institucional.

Se impone entonces una tercera respuesta, la de carácter interpretativo: algo es arte cuando hay aportación subjetiva. Este sería el secreto de la diferencia entre la caja del supermercado y la de Warhol, entre la Coca-cola servida en la cafetería y la de Jasper Johns, entre la piedra de Nelson Goodman y la que se expone en el museo. Es también el secreto que explica los cipreses de Kiarostami. Durante la excursión en coche, James comenta que cada ciprés de los que orlan el camino es un original de sí mismo, y que poseen todas las características propias de una obra artística: antigüedad, belleza..., pero al no estar en un museo nadie los contempla como obras. Falta esa mirada que hace que una cosa sea arte. Juliette Binoche le sugiere entonces incluir esa reflexión en su libro, a lo que él responde que lo hará seguramente en otro al que pondrá por título Los cipreses o el significado del arte, o quizás no.

\section{LA COPIA Y SUS ORIGINALES}

Con la pintura todo era fácil: el original era único y cada copia que se hacía de él, una copia, una falsificación.

Con la fotografía y, después, con el cine, se complicó:

el "original" era un negativo, sin copia no existía, 
al contrario: cada copia era un original. -El acto de ver, Wim Wenders-

Decíamos antes que el nombre del autor funciona como un sello de calidad que certifica el original y así permite distinguirlo de posibles copias. Al inicio de la película Copia certificada, el escritor James Miller imparte una conferencia en la que explica que la palabra "original" presenta el significado de algo "auténtico, fiable, poseedor de valor intrínseco". Como vimos en el caso de Manzoni, el gesto performativo de firmar las "esculturas vivientes" transformaba entes no artísticos -cuerpos humanos- en obras. Pero la firma del artista no tiene solo el poder de crear obras de arte, sino concretamente obras de arte originales. Las "esculturas vivientes" son, en efecto, únicas e irrepetibles, originales de sí mismas, como los cipreses del paisaje italiano. Ahora bien, ¿qué sucede con el estatus de original cuando la obra de arte forma parte de una producción serial? Las obras realizadas mediante técnicas de grabado, por ejemplo, ponen en tela de juicio la definición misma de original, cuya esencia, por así decirlo, se pluraliza, en la medida en que debe repartirse entre varias obras. Esto se resuelve considerando cada una como un original único de una tirada constituida por un número concreto de ejemplares.

Parece así reformularse el concepto de original en beneficio de una "originalidad compartida", que acredita de esta forma el especial carácter de autenticidad de cada una de las piezas que integran la serie. El propio Piero Manzoni intuyó con aguda ironía este procedimiento, que usó en las latas de "mierda de artista", etiquetadas con su respectiva numeración y así certificadas como ejemplares de un total limitado de originales. Andy Warhol le dio el giro definitivo al asunto al firmar el reverso de sus serigrafías de estilo pop, convirtiendo en original algo que de lo contrario pasaría por meras reproducciones fabricadas en serie. El caso más radical lo encontramos, sin embargo, en el polémico artista Míster Brainwash, protagonista del mockumentary Exit through the gift shop (2010) dirigido por el graffitero Banksy. En el filme se descubre el método más eficaz para transformar copias en originales: basta con colocar las serigrafías en el suelo mientras el artista es conducido en silla de ruedas a lo largo de la fila de pinturas, rociándolas con un bote de spray. Así cada obra tendrá la marca distintiva del autor, única e irrepetible. Desde esta perspectiva, la firma del autor parece lograr lo imposible: hacer de la copia un original, aunque sea una firma "en serie".

Parecidamente, en aquella industria creativa que era The Factory, Warhol y sus colaboradores trabajaban con una dinámica bien engrasada, que de hecho no resulta ajena a la propia Historia del Arte. Pensemos en el taller del pintor barroco Rubens; una eficaz máquina de producción de "Rubens" auténticos, salidos de una cadena de montaje de ayudantes y aprendices que realizaban el grueso de la obra, a falta del toque final del maestro, la marca del artista, la firma estilística apreciable en los detalles, que certificaba la obra como producto genuino. Finalmente, la burla del juego entre el original y la copia alcanza su cénit en el Arte Apropiacionista. Cuando en 1981, Sherrie Levine tomó una fotografía de la conocida instantánea de la granjera de Walker Evans y la tituló After Walker Evans, no solo estaba apropiándose del original de Evans, sino recreándolo como su propio original, el cual carecía literalmente de diferencias perceptibles respecto del primer original. La artista acomete así una especie de ready-made fotográfico. No por casualidad, a Levine se debe también la pieza titulada Fountain (After Marcel Duchamp). Si Duchamp se apropió de un urinario de fábrica para convertirlo en arte, ¿por qué no podía Levine apropiarse del urinario apropiado por Duchamp, ya consagrado como obra artística? En otras palabras, ¿por qué no podría crear un original a partir del "robo" declarado de la obra de Duchamp? Lo cual no lo convierte ni en una copia ni en una falsificación. 
Esta cadena de citaciones se prolonga aún más en el apropiacionismo digital de Michael Mandiberg, quien en 2001 creó la web AfterSherrieLevine.com, en la que el usuario podía encontrar la fotografía de la granjera de Walker Evans fotografiada por Levine, y ahora fotografiada también por Mandiberg. Se llega así a un tercer nivel de canibalismo autoral que incrementa la dificultad de la distinción entre original y copia. Además, la web fue diseñada para que se pudiese imprimir la imagen en alta resolución siguiendo las pautas del artista. Al finalizar el proceso, se descargaba en Adobe Acrobat un certificado de autenticidad. Y así, todo el mundo podía tener un "Mandiberg". Ante una propuesta artística de este tipo cabe preguntarse: ¿Hasta dónde han llegado a solaparse el original y la copia? ¿Hasta qué límite mantener una línea divisoria que los distinga? Así como Warhol entregaba al comprador un certificado de autenticidad de la obra, el certificado firmado digitalmente por Mandiberg acredita la originalidad de la fotografía, aunque esta resulte de una doble apropiación y haya sido descargada por millones de personas a través de Internet. La obra sigue teniendo el sello del artista, de modo que cada usuario imprime un "Mandinberg" original. Esta práctica artística nos recuerda, de hecho, a la web del museo de esculturas de Oliver Laric, que ya permitía descargarse imágenes "originales" de las piezas.

En un escenario como el descrito, en el que incluso las copias digitalizadas se convierten ellas mismas en originales certificados, ¿qué paradigma permitirá esclarecer semejante simbiosis operativa, resultante de la fusión entre copia y original? Quizá el concepto de "simulacro" acuñado por Jean Baudrillard facilite la clave de esta aparente contradicción. Dado que el simulacro se constituye como una "farsa veraz", supera con creces los límites de la mentira o del engaño. No se trata, en consecuencia, de un sinónimo de falsedad o fingimiento. El simulacro se identifica justamente por mezclar las fronteras definitorias de lo verdadero y lo falso. Es un fenómeno que Baudrillard caracteriza de "hipocondríaco", o sea, una falsedad cuyos efectos son muy verdaderos. "Así, pues, fingir, o disimular, dejan intacto el principio de realidad: hay una diferencia clara, sólo que enmascarada. Por su parte la simulación vuelve a cuestionar la diferencia de lo 'verdadero' y de lo 'falso', de lo 'real' y de lo 'imaginario'”. (Baudrillard 1993, 8). De modo que no es falso simular una verdad. Por extensión, la copia que se presenta como original se performa como tal al representar el simulacro de la autenticidad. A través de este procedimiento logra anular los límites diferenciales de verdad y falsedad, lo cual le permite adquirir la categoría de original en sí. Cabe pensar entonces la esencia del original como un simulacro ejecutado mediante la copia. Esto se hace especialmente evidente en el hecho de que Mandinberg establezca unas indicaciones precisas que deben seguirse para que la copia obtenida a partir de la impresión sea considerada un original. Es, por ende, el cumplimiento de estas "normas de actuación" dictadas por el artista lo que le brinda validez de original a la copia manufacturada.

Este recurso empleado por Mandinberg se asemeja a la dinámica del movimiento artístico "Doit-yourself", que pusieron en boga críticos como Hans Ulrich Obrist, y artistas como Christian Boltanski, Bertrand Lavier o Yoko Ono. De esta última son muy conocidas las Instruction pieces, consistentes en acciones realizadas por el público ajustándose a las instrucciones dejadas por la artista. Y aquí sobreviene la pregunta: ¿estas acciones son originales de Yoko Ono, o copias hechas por gente anónima? Básicamente son un simulacro en virtud del cual dichas piezas son de Yoko Ono a pesar de no haber sido hechas por ella. 0 más específicamente, las ha hecho "a distancia", ya que se han desarrollado cumpliendo sus presupuestos, así que la obra no pierde su sello autoral. El público materializa la pieza, pero limitándose a obedecer la voluntad de la artista, como si fuera una extensión de ella misma. En este panorama, la autoridad del autor es transferida por medio del simulacro. 
No en vano, si recordamos la definición que glosaba Dante en el Convivio $(2005,445)$, el autor es quien tiene poder y autoridad ("acto de autor") y de quien deriva la idea de authenticus, o también, del griego autentin, el que es digno de fe y obediencia. Quizá por eso hablaba Goodman de artes autógrafas, porque están marcadas por la autoridad del autor gracias al autógrafo -la firma del artista- en las formas inimitables que producen un original. De la película de Kiarostami se extrae, por el contrario, que no es la firma del autor lo que hace original al original, lo que certifica la obra como auténtica, sino en realidad sus copias. Como reconoce el escritor al principio del filme, por medio de su libro pretendía demostrar que la copia posee valor por sí misma puesto que nos conduce hacia el original, certificando así su valor. Observa asimismo la necesidad de autentificación, de verificación, de tener acreditada la obra como original. En respuesta a dicha tendencia sostiene un aparente oxímoron: es la copia la que certifica el original. Podríamos pensar entonces la copia como alter ego del original, como su reflejo distorsionado, un avatar que la confirma en su esencia. De suerte que el original necesitaría a su replicante para ser original. En este sentido, la copia sería a su modo tan original como el original que refrenda. Sería, por así decirlo, el original del original, aun siendo una copia de este.

Los papeles se invierten; se altera el recorrido que iba del original y su fuente de verificación, el autor, a la copia como antítesis de dicho original. Según lo argumentado por el personaje de Shimell, es al revés: el original se sabe original porque una copia lo reafirma como tal. La obra se mira en el eco especular de la copia, como el Narciso lacaniano que busca en una mirada externa la réplica de su propia existencia. Y así, solo por el esclavo es amo el señor. Matizando, pues, a Cesare Brandi, es cierto que la falsedad no es rasgo inherente al objeto, pero tampoco lo es la autenticidad. Ambas son consecuencia de su reciprocidad. La idea de que la copia, para ser copia, dependía de un original, ha dado un giro completo: el original depende de la copia para ser original. En otras palabras, es la copia la que hace que el original sea original. ¿Resultaría entonces viable pensar la copia como original, teniendo en cuenta que ahora es ella la fuente de autentificación? ¿Se podrían incluso hacer exposiciones de copias con el mismo criterio y valor que si fueran originales? En distintos países existen ya museos sin originales y exposiciones de reproducciones.

Esta circunstancia invita a repensar la concepción monolítica de museo como espacio sagrado, templo o cámara de las maravillas, que salvaguarda solo originales. Sin necesidad de alejarnos del David, en la Galleria dell' Accademia se puede visitar la sala de los yesos, atestada de copias que se exponen a escasos metros de donde se alza el majestuoso original de Miguel Ángel. Este criterio de mostrar copias junto con obras originales en salas contiguas alcanza efectos notables en los Cast Courts del Victoria \& Albert Museum de Londres. Aquí las copias se exhiben principalmente como piezas didácticas, y sin embargo, pueden provocar en el visitante una reacción equiparable al original que quizás nunca vea in situ, siendo esta copia lo más cercano que estaría de aquel. En esta casuística, la copia se constituye en el original funcional a ojos del espectador. Deviene, así, el original de un original; lo que podríamos denominar una "copia original". Este carácter de originalidad de la copia depende del original al que alude, cuya citación implícita hace que la copia funcione como original. De lo cual se deduce que es su carácter de original lo que depende del original, y no su carácter de copia. En este caso, por tanto, la copia sería un original de otro, y no solo una copia.

Ahora bien, si puedo tener una experiencia gratificante con la copia en vez de con el original, ¿qué tiene este de específico? En experiencias como la referida no es posible prescindir del original, porque la copia depende de este para funcionar como copia original. Es lo que explicaba James en su conferencia: la copia tiene valor en sí misma porque nos conduce al original, certificándolo como tal. En estas circunstancias, se disfruta la copia como original porque convoca otro original, 
el "verdadero", que asume dicho valor gracias a la copia. Una muestra de copia original es, por ejemplo, el cuadro del Museo de Lucignano que el escritor y la vendedora de antigüedades visitan en su excursión. La pintura es un retrato femenino que, según explica la guía del museo, hacía poco se había descubierto que en realidad era la copia de un original conservado en Herculano. No obstante, en el museo la habían considerado tan bella como el original y la habían reconocido como obra propia. Por eso la mostraban al público con el título Copia original. ${ }^{1}$ El personaje de Binoche defiende que esta información debe decirse para que la gente sepa que la pintura no es original, sino fruto del talento de un falsificador napolitano. Pero James le pregunta que por qué habría de saberse. "El original solo es una reproducción de la belleza de la muchacha del cuadro. Ella es el verdadero original."

Si el original era la hermosa joven, el cuadro original sería ya una copia. Y la copia, a su vez, una copia de la primera. Por extensión, observa el escritor, la pintura de Leonardo sería una copia de Mona Lisa, de su belleza, de su enigmática sonrisa, que constituyen el auténtico original. Recuerda este argumento al de la mímesis platónica en triple descenso desde el original alojado en el mundo de las Ideas hasta llegar al mundo sensible, pasando por el nivel de los artesanos, pintores y poetas, quienes hacen copias del original trascedente e imágenes falaces de tales copias, operando así una progresiva degeneración del auténtico referente. Si las personas ignoran este procedimiento dialéctico, pueden creer el engaño de que las obras son el original verdadero. De ahí la legendaria desconfianza de Platón hacia los artistas y la necesidad de educar a los jóvenes de la polis en el conocimiento de las Ideas.

La actitud defendida por la vendedora de antigüedades refrenda hasta cierto punto el objetivo platónico de saber diferenciar el modelo verdadero de la copia falsa. En su opinión, los visitantes deben ser conscientes de que lo que contemplan es una copia. A decir verdad, el mero hecho de saberlo modificaría sustancialmente su mirada y actitud hacia el objeto. Y sin embargo, aquel niño de la Piazza della Signoria, que era su propio hijo, no sabía que estaba frente a una copia porque ella no se lo había dicho. Así pues, James insiste: ¿Qué más da? Con su pregunta retórica logra desarticular la dimensión mimética de la copia, al igual que Danto rompía con la huella platónica en su análisis de las Cajas de Brillo: la obra no está en deuda con un original, sino que es original de sí. Con lo cual, nada ganamos sabiendo si la obra se estima copia u original, ya que a efectos prácticos, es original. Para el niño, la copia era original al margen del original genuino que la justifique. Por tanto, no tiene por qué saberlo. Desde este punto de vista, la copia tiene valor en sí, incluso sin necesidad de evocar un original. No estamos ya ante un original de otro original, sino ante un original propio, un original de sí mismo, autónomo, no derivado. En vez de una copia original, se trataría de un "original copia”. Asumimos, pues, que la copia puede ser un original; la cuestión es en función de qué, si es original de otro original, u original de sí mismo.

Al original pictórico de Herculano aludido en Copia certificada podríamos darle la réplica mediante el original escultórico de Pompeya que aparece en Viaggio in Italia (Rossellini, 1954), con el cual se ha relacionado precisamente la película de Kiarostami (Quintana 2011, 50). En la película de Rossellini, un matrimonio a punto de separarse asiste al desenterramiento de los restos de una pareja cubierta por las fatídicas cenizas que sepultaron la ciudad. La figura surge como un molde de nada, como huella sin referente, una imagen positivada que hubiera perdido su negativo. Es, literalmente, una copia sin original. Por tanto, un original de sí mismo. Es revelador que los arqueólogos se refieran a estas piezas como los "moldes de Pompeya", si bien en años recientes, nuevos escaneos han descubierto restos óseos en algunas de ellas. Esto no es óbice, sin 
embargo, para considerar dichos moldes copias de originales inexistentes y mayormente perdidos. Caso distinto serían, por ejemplo, los moldes de originales vivos a los que recurría Rodin para el vaciado de sus naturalistas bronces. Los moldes pompeyanos son copias que carecen de original, al contrario que la pintura de Lucignano. Con más motivo, son originales de sí y pueden denominarse original copia.

No obstante, estos mismos moldes pueden abordarse también como si fueran los yesos de la Accademia o del Victoria \& Albert, esto es, teniendo presente la referencia indirecta de sus originales. Siendo así no resulta difícil comprender la honda impresión que su desenterramiento provoca en una emocionada Ingrid Bergman en el filme de Rossellini, quien al ver la copia estaría evocando a la pareja original que pereció en la erupción. En tal caso los moldes funcionarían como copia original. Salta a la vista que se diversifica cada vez más el criterio para delimitar la frontera entre original y copia, que se borra progresivamente. Y esto no porque hayan llegado a ser lo mismo. Que la copia sea un original no significa que sea lo mismo que el original, sino que la categoría de original se hace plural. Hablaríamos entonces de varios originales. El original único, referencia de verdad, que negaba valor ontológico a las copias, pierde primacía para dar cabida a otros originales. A la salida del museo concluye Juliette Binoche: "Entonces, ¿está diciendo usted que no hay originales, verdad?" "No, hay originales de sobra”, replica James. En efecto, lo que no hay son copias.

\section{CODA: EL AURA DE LA COPIA}

Se podría decir que los originales se preservan mediante las copias. -Shanzhai, Byung-Chul Han-

Según lo dicho, el David de la Piazza della Signoria sería un original de entre los infinitos que existen. Llevando esta fórmula al extremo, ¿sería legítimo poner al mismo nivel el David de la Accademia y las copias baratas que compran los turistas en tiendas de souvenir? Autores de la Escuela de Frankfurt como Horkheimer y Adorno dirigieron una profunda crítica al sistema consumista de la industria cultural y el arte de masas, que da a las obras el tratamiento reificado de una mercancía o fetiche comercial. Si según estos teóricos de inspiración marxista, hoy día la obra de arte se estima desde su valor exhibitorio-simbólico, y no tanto desde el valor de intercambio o de uso, no es de extrañar el deseo generalizado de posesión. Todos querríamos disponer del original, pero son solamente unos pocos privilegiados, asiduos de casas de subastas y galerías de arte, quienes tienen capacidad adquisitiva para permitírselo. Ante esta imposibilidad de disfrutar como dueños del original, nos contentamos con su versión plebeya: la copia, la falsificación, el producto fake. Este objeto sin pedigrí se convertirá en nuestro original, en el original propio de quien lo ha comprado, que opera así en tanto que remite al original al cual aspiramos, como si de una porción o fragmento de aquel se tratara. De ahí su paralelismo con el fetiche freudiano, como extracto parcial del objeto total que despierta nuestro deseo.

A partir de Pierre Bourdieu, podríamos argumentar que la obra recibe una lectura fetichista por el campo que instituye la creencia en el valor de la obra del artista genio, es decir, por la creencia colectiva del juego (illusio) y hábito cultural en el revestimiento sagrado de sus reglas. De forma que al comprar el souvenir del David estaríamos comprando, por así decir, una parte del aura del original, de su aureola de objeto venerable y único. La copia es, en este sentido, un fetiche que 
pone al individuo en contacto con el poder irradiado por el original. Es por eso que decoramos nuestra vivienda con reproducciones kitsch de bustos en yeso del David de Miguel Ángel o láminas enmarcadas de Mona Lisa. De hecho, sucede lo mismo cuando compramos falsificaciones de marcas de ropa o complementos. No importa vestir una falsificación -de hecho compramos el producto a sabiendas de que lo es- porque lo que interesa es el concepto asociado al objeto, una falsa imagen de exclusividad. Es su valor simbólico lo que adquirimos.

Esta idea es criticada por el artista filipino Pío Abad en la instalación Not A Shield, but a Weapon (2016), compuesta por cien bolsos de mano originales inspirados en el modelo Asprey que popularizó Margaret Thatcher. Si un objeto de uso común, como un bolso, se ubica en un museo, se mira como obra artística. Pero, ¿un bolso Chanel, por ejemplo, no se considera ya de por sí una "obra de arte"? Jeff Koons complica la situación al diseñar una colección exclusiva de bolsos Louis Vuitton con el estampado de cuadros de Van Gogh, Rubens, Tiziano... Híbrido de producto comercial y obra de arte, esta propuesta incide en el deseo del original, y al mismo tiempo alaba y promueve la falsificación. Esto nos recuerda que en Copia certificada, la vendedora de antigüedades comenta que a su hermana Marie le encanta la bisutería: las joyas falsas, siendo asequibles para todos, se ven como las auténticas y cumplen su propósito igual que el original. Nos parece encontrar aquí de nuevo al niño para quien la copia del David funciona como el original. Lo cierto es que, a simple vista, sobre todo si la copia es de calidad, no es fácil distinguir una joya falsa de la auténtica. En efecto, la clave de esta diferencia no radica, como sabemos, en la percepción a nivel epistemológico.

Como se dice en la película, la ventaja de las joyas de imitación es que plantean menos problemas que las originales, son más prácticas y sirven igual. Es por eso que a Marie le entusiasmó el libro de James: "Mejor una buena copia que el original". Esta declaración la podría haber hecho Andy Warhol, quien al reproducir la imagen de Mona Lisa como si de Marilyn Monroe se tratara, tituló la serigrafía Treinta son mejor que una (1963). La osadía de Warhol llega al extremo de afirmar que tener a Mona Lisa treinta veces es mejor que solo el original. ¿Por qué iba a contentarme con una Mona Lisa si puedo tener treinta? Esto no es del todo paradójico si, como se ha dicho antes, el cuadro de Leonardo era ya una copia de Mona Lisa. En cualquier caso, lo que certifica el afán reproductor de Warhol es la pérdida del aura del original. ¿Qué importa multiplicar la obra hasta la saciedad? ¿Qué problema hay con hacer copias hasta el hartazgo? A este respecto, Binoche explica que su hermana es una persona simple y sin pretensiones: "Vive en su mundo, donde no hay diferencia entre la copia y el original". Pero James advierte que no es nada simple ser una persona simple. En efecto, esta persona "simple" dota al objeto de un nivel simbólico, transfiriéndole la cualidad de fetiche (copia original), o bien convirtiéndolo en un original propio (original copia).

Así pues, ¿tiene sentido igualar el David de Miguel Ángel y los David .made in China"? Dado que la copia es ahora la que certifica la originalidad del original, el criterio tradicional de autenticidad parece haberse diluido. La firma del autor ya no tiene la última palabra. Es como si el sello de autoridad de Miguel Ángel estuviera refrendado por otros "hacedores" del David. Dicho de otro modo, es porque se hacen souvenirs del David que la gente conoce el David, lo identifica como obra maestra y lo convierte en icono del imaginario cultural. Es más, incluso delante del original mismo seguimos viendo un souvenir, solo que de dimensiones colosales. Este es el aura actual de la obra de arte. El homo turisticus que visita el Museo del Louvre aguarda pacientemente su turno para estar dos segundos delante de Mona Lisa, lo suficiente para tomarse un selfie con el cuadro, es decir, para ver la obra-souvenir de Leonardo. Si Mona Lisa no hubiera sido protagonista de un sonado robo y catapultada como estrella mediática de la prensa y publicidad de la época, su imagen no se habría reproducido en multitud de objetos y postales, y hoy día no se consideraría la obra más famosa del 
mundo. En resumen, el valor del original en el tiempo del capitalismo cultural es el que es porque se han hecho copias al infinito. El original necesita de su souvenir para existir.

Una vez más, no es el original el que ratifica las copias, sino las copias las que hacen original al original. Al mismo tiempo nivelan la ontología de este: tan souvenir es el David que se expone en la Accademia como el que se compra de recuerdo, porque a decir verdad, ambos operan como originales, esto es, como originales de consumo. El original de Miguel Ángel lo es en tanto que mercancía -cultural- consumible. Entonces, ¿cómo diferenciarlos ontológicamente? Nos seguimos haciendo la misma pregunta que se hacía Danto ante las Cajas de Brillo. Y es que, siendo todos objetos originales, no todos lo son del mismo modo. El simulacro consumista, que les da un revestimiento kitsch, dibuja el escenario propicio para buscar la originalidad de la copia en el fenómeno shanzhai. Byung-Chul Han ha estudiado este neologismo chino, sinónimo de fake, que refiere objetos de moda que no ocultan ser falsificaciones de marcas famosas: "Los productos shanzhai no pretenden engañar a nadie. Su atractivo consiste precisamente en que ellos mismos indican de manera expresa que no son un original, sino que juegan con este". $(2016,79)$

Como explica el filósofo surcoreano, los chinos adoran la copia y no tienen inconveniente en prescindir del original, pues para ellos no existe diferencia remarcable entre este y aquella. El original prescinde del halo sacrosanto e inviolable que se le atribuye en Occidente, pudiendo afirmarse que en la tradición oriental no existe el esencialismo del original. "La idea del original chino no se entiende como una creación única sino como un proceso infinito, no apunta a la identidad definitiva sino a la transformación incesante". (Han 2016, 21) Esta fundamental diferencia entre Oriente y Occidente ha suscitado en ocasiones anécdotas reveladoras, que quiebran el reconocimiento de verdad que se le presupone al original y ensalzan el valor de falsificaciones que no se pretendían tales. ${ }^{2}$ Esto se explica porque en el pensamiento chino el original no es concebible como identidad estable y permanente, sino como entidad plural y procesual. Por eso dice ByungChul Han que una obra de arte china nunca se mantiene idéntica a sí misma, sino que evoluciona y atraviesa su propia biografía. De esto es testimonio la costumbre de marchantes y coleccionistas de ir aplicando sucesivamente sus sellos de tinta sobre una misma pintura. Estos sellos no son una firma que certifica la obra como original, sino que introducen una ruptura, una apertura hacia un discurso deconstructivo que evidencia el desarrollo vivo de la pintura. Al contrario que en Occidente, en China, cuanto más popular resulta una obra, más manipulable es, menos intacta se conserva. Nada que ver, en efecto, con las firmas de Manzoni o Warhol:

Los sellos que pueden verse en los cuadros antiguos chinos son muy distintos de las firmas de la pintura europea. No son expresión de la autoría, que vendría a autentificar la imagen y hacerla excepcional. La mayoría de los sellos son obra, más bien, de los expertos o los coleccionistas, que se inscriben en las imágenes no solo por medio de esas marcas, sino también de sus comentarios. [...] En las pinturas chinas, las estampas de los sellos no sellan nada. Más bien abren un espacio comunicativo. No dotan a la imagen de una presencia autoral, autoritaria. En ese punto se diferencian claramente de las firmas de los cuadros europeos. (Han 2016, 53-54)

Desde este punto de vista se comprende mejor la macromáquina industrial china y su vasto comercio de productos de imitación. Prácticamente la totalidad de souvenirs que se compran en Europa, con los iconos más populares de su cultura, son fabricados en China. Ironías aparte, el caso más significativo es la localidad china de Dafen, un suburbio dedicado a la reproducción masiva de pinturas famosas que se venden en el mercado internacional como copias de la más alta calidad. El sistema de trabajo establecido en Dafen destruye de forma explícita los criterios tradicionales de distinción entre copia y original. ${ }^{3}$ Sabedores de que el original es inaccesible, responden a la 
demanda del fetiche comercial. Desde una perspectiva occidental, parece que esta práctica le pierde el respeto a la obra. No en vano declaraba Walter Benjamin que la reproductibilidad mina la noción de autenticidad. Esto no se percibe de la misma manera en Oriente; como observa Han, no es casualidad que la imprenta se inventase en China. En el célebre texto de Benjamin La obra de arte en la época de su reproductibilidad técnica se define el aura como "aparecimiento único de una lejanía" inherente a la obra, que por ende, se presenta esencialmente inaccesible $(2003,47)$. Sin embargo, con la reproducción técnica y difusión masiva de copias, se torna repetible y cercana, se impone con una presencia ubicua. Huelga decir que la pérdida del aura vaticinada por Benjamin constituye un aspecto latente a lo largo de todo el filme de Kiarostami.

La lejanía de la obra, antes vinculada al ritual cultual, sucumbe a la irrupción de las masas y su deseo de consumo, mutando en valor exhibitivo. ${ }^{4}$ La decadencia del aura acontece, por tanto, cuando la obra pierde su carácter único a causa de la reproducción. Sufre así la atrofia de su aura, masificada, desacralizada, profanada. Asistimos a un proceso de desteologización del original. En consecuencia, considera Walter Benjamin que las nuevas tecnologías reproductivas, aun no dañando el original, lo perjudican seriamente. "Por lo demás, aunque estas nuevas condiciones pueden dejar intacta la consistencia de la obra de arte, desvalorizan de todos modos su aquí y ahora" $(2003,44)$, cualidades que, en su opinión, constituyen la esencia del original. Ahora bien, dicho esto, quizá las copias, al difundir la imagen del original, no le restan aura. En realidad, el aura todavía no se ha perdido del todo, sino que más bien se ha transformado. En la expresión de José Luis Brea, se ha enfriado.

El aura ha sido tradicionalmente un rasgo candente de la obra, que en tiempos recientes se ha vuelto latente, pero que no ha desaparecido por completo. Siendo antes un aspecto palpable y notorio, con la reproductibilidad técnica se ha enfriado y apagado, aunque no por ello consumido. El aura sigue existiendo, lo que ocurre es que lo hace en la dialéctica entre original y copia, como si el primero hubiera transferido a sus réplicas el poder aurático. Es ahora el fetiche comercial, ese "original made in China", el que certifica la obra, porque, irónicamente, es él quien preserva su aura. De modo que si la obra original todavía conserva algo de aura es gracias a la difusión de sus copias. De no ser así, ¿por qué seguiríamos peregrinando al museo para fotografiarnos con Mona Lisa? Lo hacemos porque el original es hoy día una extensión justificada gracias a su doble mediático. Es por la copia que nos acercamos al original. En definitiva, el original sigue teniendo aura, aun reproducido, porque se ha transformado en souvenir y ha adquirido el aura del icono de masas: un aura frívola, superficial, cuyo ritual no es cultual sino consumista.

Así, lo que Brea llamaba "efecto Duchamp" ha llegado a su máximo desarrollo. El sacrum del original, lejos de haber muerto a manos del progreso tecnológico, se ha metamorfoseado: la lejanía aurática camina hacia su secularización y democratización. Se trata de un cambio de paradigma del aura, que en vez de desaparecer se pone a tono con su tiempo. "Así, preferimos sugerir que más que a una desaparición del aura es a una variación -un enfriamiento- de su temperatura a lo que asistimos. A una variación de las temperaturas que sí, ciertamente, tiene que ver con un desplazamiento de la significación en una dirección secularizadora”. Persiste, por tanto, el aura, aunque fría y sin reverencia litúrgica. El culto que ahora recibe el original es el del espectáculo. Lo que antes era aura, se ha convertido en auras por la "reproductibilidad telemática"; se ha expandido y diluido en la "ubicuidad generalizada" de una "estetización difusa". Bajo estos parámetros, Brea insiste en que la multiplicación del original incrementa no ya su cobertura sacra, sino fetichista. Por lo tanto, no es que el original pierda su aura, sino que, como subrayan Latour y Lowe (2011), 
esta se mantiene por la reproducción técnica (facsimile). Boris Groys (Smith (eds.) 2008) observa incluso la proliferación de museos "sin objeto", donde el aura del original reside en la exhibición de su copia digital.

El aura del original se ha transferido a sus copias, y ahora estas le otorgan aura a aquel. En conclusión, sería, pues, más exacto hablar del aura de la copia. La copia, vista como original, tiene también aura. Así las cosas, la copia no debilita al original, sino que lo refuerza, aunque de forma

fetichista. ${ }^{5}$ En esta línea, y con las salvedades realizadas, se podría afirmar que la copia es más original que el original. Así pues, ¿seguimos queriendo el original? ¿O nos vale una buena copia?

\section{REFERENCIAS}

Adorno, Theodor W. Teoría estética. Obra completa, vol. 7, Madrid: Akal, 2004.

Alighieri, Dante. Convivio. Madrid: Cátedra, 2005.

Barthes, Roland. El susurro del lenguaje. Más allá de la palabra y de la escritura. Barcelona: Paidós, 1994.

Baudrillard, Jean. Cultura y simulacro. Barcelona: Kairós, 1993.

Benjamin, Walter. La obra de arte en la época de su reproductibilidad técnica. México: Itaca, 2003.

Bourriaud, Nicolas. Estética relacional. Buenos Aires: Adriana Hidalgo editora, 2008.

Brandi, Cesare. Teoría de la restauración. Madrid: Alianza, 2003.

Bray, Maryse y Calatayud, Agnes. "The truth about lies: the relationship between fiction and reality in Abbas Kiarostami's Certified Copy." New Readings, no. 11 (2011): 84-99.

Brea, José Luis. Las auras frías. El culto a la obra de arte en la era postaurática. Creative Commons, 2009. joseluisbrea.net/ediciones_cc/auras.pdf

Carmona Hurtado, Jordi. “Aura y fetiche." Nómadas. Revista Crítica de Ciencias Sociales y Jurídicas 13, no. 1 (2006): 91-104.

Danto, Arthur C. ¿Qué es el arte? Barcelona: Paidós, 2013.

Dickie, George. El círculo del arte. Barcelona: Paidós, 2005.

Goodman, Nelson. Los lenguajes del arte. Aproximación a la teoría de los símbolos. Madrid: Paidós, 2010.

Goodman, Nelson. Maneras de hacer mundos. Madrid: Visor, 1990.

Groys, Boris. Bajo sospecha. Una fenomenología de los medios. Valencia: Pre-Textos, 2008.

Groys, Boris. "The Topology of Contemporary Art." In Antinomies of Art and Culture. Modernity, Postmodernity, Contemporaneity, edited by Terry Smith \& eds., 71-80. Durham \& London: Duke University Press, 2008.

Han, Byung-Chul. Shanzhai. El arte de la falsificación y la deconstrucción en China. Buenos Aires: Caja Negra Editores, 2016.

Jiménez, José. Teoría del arte. Madrid: Tecnos, 2004.

Latour, Bruno y Lowe, Adam. "The migration of the aura or how to explore the original through its facsimiles." In Switching Codes: Thinking Through Digital Technology in the Humanities and the Arts, edited by Thomas Bartscherer, 275-298. Chicago: University of Chicago Press, 2011.

Mecacci, Andrea. "Aesthetics of Fake. An Overview." Aisthesis. Pratiche, Linguaggi e Saperi Dell' Estetico. Rivista on-line del Seminario Permanente di Estetica IV, no. 2 (2016): 58-69.

Nietzsche, Friedrich. Crepúsculo de los ídolos o Cómo se filosofa con el martillo. Madrid: Alianza, 1998.

Quintana, Ángel. Después del cine: Imagen y realidad en la era digital. Barcelona: Acantilado, 2011.

Schwartz, Hillel. La cultura de la copia. Parecidos sorprendentes, facsímil insólitos. Madrid: Frónesis, Cátedra, Universitat de València, 1996. 
Wong, Winnie. Van Gogh on Demand: China and the Readymade. Chicago: University of Chicago Press, 2014.

Notas

1 "The information we glean from the film, though plausible, is Kiarostami's invention. A case in point is the painting called Musa Polimnia, in real life housed in Cortona, but which in the film is presented as the highlight of Lucignano's museum. The Musa Polimnia is the portrait of a young Roman woman hold in galyre, found in a nearby field during excavations in the eighteenth century, although a controversy rages over its origin. Contrary to what the museum guide claims, in words chosen by Kiarostami, there is no original of this painting in Herculaneum or anywhere else, but the viewer is led to believe that the Musa Polimnia is a copy. The guide refers to it as 'a real copy; it's like the Gioconda della Toscana'. This invented story in the film serves well Kiarostami's avowed aim of questioning the real-copy dichotomy." Bray, Maryse y Calatayud, Agnes. "The truth about lies: the relationship between fiction and reality in Abbas Kiarostami's Certified Copy." New Readings, no. 11 (2011): 90. "Cuando se supo que los guerreros chinos de terracota que se expusieron el Museo de Etnología de Hamburgo en 2007 eran una copia, se clausuró la exposición. El director del centro, que se erigió en defensor de la verdad, declaró en ese entonces: 'Hemos llegado a la conclusión de que no tenemos otro remedio que cancelar la exposición para mantener la reputación del museo'. Incluso se ofrecieron a devolver el dinero de la entrada a todos los visitantes que habían acudido. Desde el comienzo de la excavación arqueológica se llevó a cabo, de manera paralela, la fabricación de las réplicas de los guerreros de terracota. Junto a la excavación se abrió un taller de copias. Pero en ningún caso confeccionaban 'falsificaciones'. Para hablar con propiedad, habría que decir que los chinos estaban intentando retomar la producción, que en ningún momento fue una creación. Los propios originales formaban parte de una producción en serie con módulos, en realidad adornos móviles, que podía proseguirse siempre que estuviera a disposición la técnica de fabricación. [... ] La discrepancia en cuanto a la interpretación de la copia a menudo ha generado malentendidos y controversias entre China y los museos occidentales. Los chinos a menudo mandan copias en vez de originales, puesto que están convencidos de que en lo esencial no son distintos. Se tomaron el rechazo por parte del museo occidental como una ofensa". Han, Byung-Chul. Shanzhai. El arte de la falsificación y la deconstrucción en China. Buenos Aires: Caja Negra Editores, 2016, 61-62.

3 “Like Duchamp's, then, Dafen's “readymades" are far from off-the-rack factory products, but are made after a known but inaccesible original, ordered by a client who supplies an image from which the painter proceeds with this work of remaking. In Dafen, this image, passed to the painter in the form of a printed photograph, a pronted illustration in a book, or a digital file transferred by instant message or email, is referred to as a gao -a Chinese word that means a 'manuscript copy', or a 'draft"'. Wong, Winnie. Van Gogh on Demand: China and the Readymade. Chicago: University of Chicago Press, 2014, 17.

4 "En la reproducción algo se gana y algo se pierde en términos de valor de la obra de arte: gana en valor exhibitivo pero pierde en valor cultual. [...] La obra de arte de carácter aural se distingue por dos rasgos principales: en primer lugar, no es comprensible sino en el ámbito de la tradición en la que surge, en segundo lugar, su presencia es irrepetible. La reproducción trastorna a estos dos caracteres, pues desvincula la obra del contexto de su tradición y le otorga una presencia masiva. [... ] La obra de arte, o tiene valor cultual, o lo tiene exhibitivo. El aura no es transmisible, conforma, como lo llama Benjamin, el aquí y ahora de la obra de arte". Carmona Hurtado, Jordi. “Aura y fetiche.” Nómadas. Revista Crítica de Ciencias Sociales y Jurídicas 13, no. 1 (2006), 97. "Walter Benjamin, un teórico que para algunos lectores podría haber estado latente tras estas páginas, no acertó al decir que, con la réplica, el original ha perdido su aura. Se equivocó al pretender que la distancia ritual que mantenemos -o por la que somos mantenidos- con respecto a la obra de arte única había disminuido a causa de los modernos procesos industriales. Lo que se debilita en la era de la reproducción no es el aura de las obras de arte, sino la seguridad de nuestra propia vitalidad. [... ] Solo en una cultura de la copia le asignamos dicha fuerza motivadora al original. Lo que entendemos por 'original' hoy día es lo que nos habla de manera inmediata, una experiencia que creemos haber perdido entre nosotros los humanos. Si Benjamin, el coleccionista de libros, vio certeramente que 'cada día se hace más fuerte la necesidad de poseer un objeto muy cercano a través del parecido, de su reproducción', no supo comprender que dicha posesión es pentecostal en última instancia, un deseo que traduce nuestras dolorosas semejanzas a ser trasladados a nuestra verdadera naturaleza y a poseer el don de lenguas". Schwartz, Hillel. La cultura de la copia. Parecidos sorprendentes, facsímil insólitos. Madrid: Frónesis, Cátedra, Universitat de València, 1996, 132-133. 